\title{
Increased amount of atrial fibrosis in patients with atrial fibrillation secondary to mitral valve disease
}

\author{
Guillaume S. C. Geuzebroek, MD, ${ }^{\text {acc }}$ Shirley C. M. van Amersfoorth, RA, ${ }^{c}$ Mark G. Hoogendijk, MD, PhD, ${ }^{\text {b,c }}$ \\ Johannes C. Kelder, MD, PhD, ${ }^{\mathrm{b}}$ Norbert M. van Hemel, MD, PhD, Jacques M. T. de Bakker, PhD, ${ }^{\mathrm{c}, \mathrm{d}}$ and \\ Ruben Coronel, $\mathrm{MD}, \mathrm{PhD}^{\mathrm{c}}$
}

\begin{abstract}
Objective: Atrial fibrosis is related to atrial fibrillation but may differ in patients with mitral valve disease or lone atrial fibrillation. Therefore, we studied atrial fibrosis in patients with atrial fibrillation + mitral valve disease or with lone atrial fibrillation and compared it with controls.
\end{abstract}

\begin{abstract}
Methods: Left and right atrial appendages amputated during Maze III surgery for lone atrial fibrillation $(\mathrm{n}=85)$ or atrial fibrillation + mitral valve disease $(n=26)$ were embedded in paraffin, sectioned, and stained with picrosirius red. Atria from 10 deceased patients without a cardiovascular history served as controls. A total of 1048 images (4- $\mu \mathrm{m}$ sections, 10 -fold magnification, 4 images per appendage) were obtained and digitized. The percentage of fibrous tissue was calculated by quantitative morphometry.
\end{abstract}

\begin{abstract}
Results: Irrespective of the presence or absence of atrial fibrillation or mitral valve disease, more fibrous tissue was present in right atrial appendages than in left atrial appendages $(12.7 \% \pm 5.7 \%$ vs $8.2 \% \pm 3.9 \%$; $P<.0001)$. The mean amount of fibrous tissue in the atria was significantly larger in patients with atrial fibrillation + mitral valve disease than in patients with lone $\mathrm{AF}$ and controls $(13.6 \% \pm 5.8 \%, 9.7 \% \pm 3.2 \%$, and $8.8 \% \pm 2.4 \%$, respectively; $P<.01$ ). No significant differences existed between patients with lone atrial fibrillation and patients without a cardiovascular history (controls).
\end{abstract}

Conclusions: Atria of patients with atrial fibrillation and mitral valve disease have more fibrosis than atria of patients with lone atrial fibrillation. However, patients with lone atrial fibrillation have an equal amount of atrial fibrosis compared with controls. These findings support the notion that fibrosis plays a more important role in the pathogenesis of atrial fibrillation secondary to mitral valve disease than in lone atrial fibrillation and potentially explains the relatively poor success of antiarrhythmic surgery in patients with mitral valve disease. (J Thorac Cardiovasc Surg 2012;144:327-33)

Atrial fibrillation (AF) is the most common sustained arrhythmia in humans and has an increased prevalence in elderly patients and patients with mitral valve disease (MVD), heart failure, hypertension, or pulmonary disease. ${ }^{1}$

Both electrical and structural remodeling of the atria play an important role in the pathogenesis of $\mathrm{AF}^{2}$ Experimental and clinical investigations have shown a relation between atrial interstitial fibrosis and AF with or without structural heart diseases. ${ }^{3-5}$ Fibrosis resulting from chronic atrial dilatation and stretch may cause $\mathrm{AF}^{6}{ }^{6}$ whereas $\mathrm{AF}$ itself may cause atrial fibrosis because of structural remodeling. ${ }^{2}$

\footnotetext{
From the Departments of Cardiothoracic Surgery ${ }^{\mathrm{a}}$ and Cardiology, ${ }^{\mathrm{b}}$ St Antonius Hospital, Nieuwegein, The Netherlands; Department of Experimental Cardiology, ${ }^{\mathrm{c}}$ Academical Medic Center Amsterdam, Amsterdam, The Netherlands; and The Interuniversity Cardiology Institute of the Netherlands, ${ }^{\mathrm{d}}$ Utrecht, The Netherlands. Disclosures: Authors have nothing to disclose with regard to commercial support. Received for publication May 12, 2011; revisions received Aug 10, 2011; accepted for publication Sept 21, 2011; available ahead of print Oct 19, 2011.

Address for reprints: Guillaume S. C. Geuzebroek, MD, Koekoekslaan 1 PO Box 2500, 3430 EM Nieuwegein The Netherlands (E-mail: G.S.C.Geuzebroek@ gmail.com).

0022-5223/\$36.00

Copyright (C) 2012 by The American Association for Thoracic Surgery

doi:10.1016/j.jtcvs.2011.09.022
}

The amount of fibrous tissue probably affects the success of nonmedical therapy directed at AF suppression and prevention, such as Maze(-like) surgery. Although surgery directed against $\mathrm{AF}$ can be effective in the treatment of lone $\mathrm{AF}$, it is less effective in the treatment of AF secondary to MVD. $^{7}$

Organized lines of fibrotic scar tissue created by Maze(-like) surgery prevents AF by reducing the tissue mass that could sustain reentry. Diffuse interstitial fibrosis also reduces the electrical tissue mass but facilitates reentry arrhythmias via 2 mechanisms. First, it forms barriers of nonconductive tissue that can lead to longer activation paths ("zigzag" conduction) with mainly transversal conduction slowing and thus increased anisotropic conduction, which is associated with reentry. ${ }^{8,9}$ The "zigzag" conduction locally prolongs atrial activation time and thereby shortens the dimension of a potential reentrant activation path. Second, these barriers create geometric variation within the myocardium and cause sites of sudden myocardial expansion that can lead to current-to-load mismatch. ${ }^{10}$ Both mechanisms promote the occurrence of unidirectional conduction block, which is a prerequisite for the initiation and persistence of reentry arrhythmias, such as AF. 


\section{Abbreviations and Acronyms \\ $\mathrm{AF} \quad=$ atrial fibrillation \\ ASD $=$ atrial septal defect \\ LAA $=$ left atrial appendage \\ MVD $=$ mitral valve disease \\ RAA $=$ right atrial appendage}

Because AF is associated with MVD and more difficult to treat than lone $\mathrm{AF},{ }^{1,7}$ we hypothesized that atria of patients with AF and MVD contain more diffuse fibrotic tissue than atria of patients with lone AF. Furthermore, comparison of the fibrous tissue content in atria of patients with lone AF with that of control patients without a history of AF may elucidate fibrosis secondary to AF. A secondary study objective was the assessment of predictors for the amount of fibrous tissue in the atria. We therefore analyzed left atrial appendages (LAAs) and right atrial appendages (RAAs) and collected clinical data of patients who had undergone surgery for AF with or without mitral valve surgery. Postmortem tissues for control were obtained from patients without a cardiovascular history.

\section{MATERIALS AND METHODS Study Population}

All tissue samples were obtained at the St Antonius Hospital, Nieuwegein, The Netherlands. The study was in accordance with the declaration of Helsinki and approved by the institutional review board. The study conformed to our local institutional protocol, which describes the use of human tissues for research. Data were anonymously and retrospectively collected. In accordance with our local protocol, no informed consent was necessary because the tissue samples were resected as part of standard therapy or diagnosis.

LAAs and RAAs were routinely removed during elective classic Maze III surgery without (lone AF) or with mitral valvuloplasty or mitral valve replacement $(\mathrm{AF}+\mathrm{MVD})$. The lone $\mathrm{AF}$ group consisted of 85 patients who had undergone a classic Maze III procedure only and included 6 patients with a small type II atrial septal defect (ASD). These ASDs were peroperatively detected by coincidence, could be closed without a patch, were not visible on echocardiography peroperatively, and were therefore considered to have no significant hemodynamic consequences. All other ASDs (type I or II) were excluded. The group with AF and mitral valve surgery comprised 26 patients. Inclusion criteria for Maze III surgery have been described in detail. ${ }^{11}$

Patients without a cardiac history served as controls. Tissue samples for the control group were obtained from hearts of 10 deceased patients after permission for autopsy from relatives. LAAs, RAAs, and samples of the left and right atrial free wall were gathered from this group. Causes of death were alcohol abuse $(\mathrm{n}=2)$, cardiogenic shock after acute myocardial infarction (without a cardiac history, $\mathrm{n}=1$ ), respiratory failure due to chronic obstructive pulmonary disease $(n=1)$, hepatic coma $(n=1)$, metastasized small cell lung carcinoma $(n=1)$, metastasized rectum carcinoma $(\mathrm{n}=1)$, sepsis with known non-Hodgkin lymphoma $(\mathrm{n}=1)$, sepsis eci $(n=1)$, and cerebrovascular attack $(n=1)$. There was no documentation or suspicion of $\mathrm{AF}$ in the medical history of the control patients.

\section{Collected Patient Data}

Pre-, peri-, and postoperative data were retrospectively collected from inpatient and outpatient hospital files of the patients who had undergone a Maze III procedure. These included patient demographics, medication, echocardiographic data, left- and right-sided pressure, and type of surgery.

Collected patient data entailed age, gender, length, weight, previous catheter ablations, type of $\mathrm{AF}$, duration of $\mathrm{AF}$, serum creatinine, history of diabetes mellitus, and blood pressure. The last 3 blood pressure recordings before surgery were noted. AF was classified as paroxysmal, persistent, or permanent. We deviated from the Heart Rhythm Society's consensus article ${ }^{12}$ because this consensus was not available at the time of operation.

The use of angiotensin inhibitors, statins, aldosterone antagonists, and antihypertensive drugs during the last 3 months before operation and amiodarone use anytime before operation were noted.

Echocardiographic data consisted of the left atrial diameter (long parasternal axis), right atrial diameter (long axis in 4-chamber view), left ventricular end-diastolic/systolic diameter, and left ventricular ejection fraction. From the catheterization records, we obtained wedge pressure; right atrial pressure; left ventricular systolic and diastolic pressures; right ventricular systolic pressure; and diastolic, systolic, and mean pulmonary artery pressures.

\section{Histology}

Tissue samples were fixed in $4 \%$ buffered formalin immediately after excision. After fixation, tissues were embedded in paraffin, and $4-\mu \mathrm{m}$ transversal sections at the base of the appendages were cut and stained with picrosirius red for visualization and quantification of collagen in the fibrous tissue.

Four digital pictures were taken with a $10 \times$ objective at $3,6,9$, and 12 o'clock of the tissue sections. Background, perivascular, endocardial fibrosis, and epicardial fibrosis were excluded by manually revising every picture with Adobe Photoshop 9.0 (Adobe Systems Inc, San Jose, Calif) (Figure 1). Thereafter, the amount of fibrous tissue was calculated by quantitative spectrometry with Image-pro 6.2 (Media Cybernetics Inc, Bethesda, Md). The percentage of fibrous tissue was expressed as the amount of red (collagen) relative to the total amount of tissue (perivascular, endocardial, and epicardial fibrous tissue excluded). A total of 1048 pictures were taken, revised, and analyzed without any knowledge of the patient characteristics.

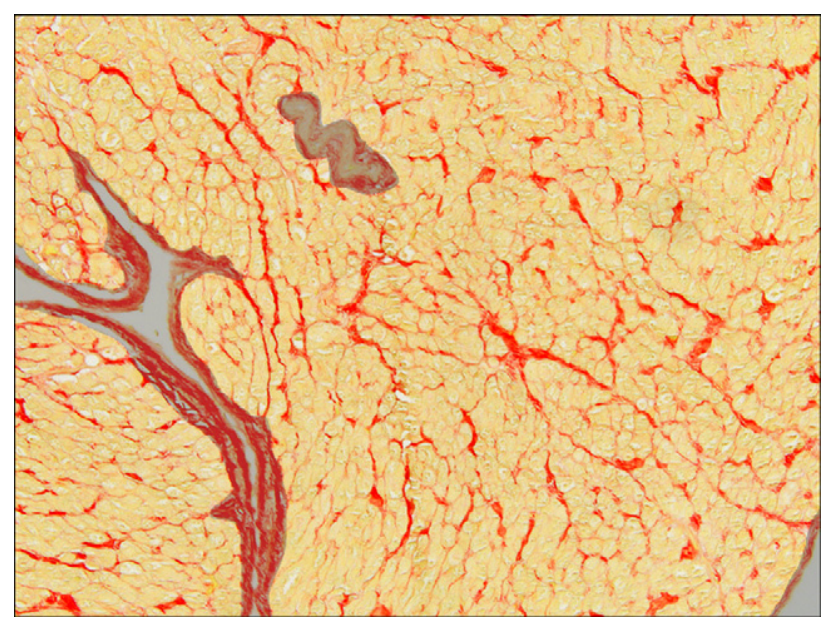

FIGURE 1. Picrosirius red staining of a $4-\mu \mathrm{M}$ section from the LAA at $10 \times$ magnification. Fibrous tissue is stained red, and (atrial) myocardium is stained yellow-orange. Background, perivascular, endocardial fibrosis, and epicardial fibrosis are excluded from quantification (grey areas). 


\section{Statistics}

Values are presented as mean \pm standard deviation, percentages \pm standard deviation, or different when indicated. Continuous variables were compared with paired Student $t$, unpaired Student $t$ test, Mann-Whitney test, or analysis of variance test with post hoc Tukey honestly significant difference comparison, where appropriate. Categoric variables were compared with the Pearson's chi-square test with Yates' continuity correction. For correlation, the squared Pearson correlation coefficient was computed along with a scatter plot for visual inspection.

The distribution of the percentage fibrosis in the atrial appendages was skewed to the right and near normal after log-transformation. For the univariate statistics, we used the nontransformed data to keep the original units. For the multivariate analysis, we used the log-transformed data. The multivariate analysis consisted of linear regression with logtransformed percentage fibrosis in the atrial appendage as the dependent variable. All variables with $P<.1$ in a bivariate analysis were candidate independent variables for the multivariate regression. We used generalized linear modeling, and the best multivariate model emerged after ranking of all possible models by the Akaike's information criterion, which is a measure of the goodness of fit of an estimated statistical model.

For the repeated-measurements analysis involving right- and left-sided atrial fibrosis as separate values in 1 patient, we used a generalized linear mixed-effects modeling with fibrosis as the dependent variable and individual as random intercept, disease with 3 categories (AF+MVD, lone AF, and control), left or right side, and the natural logarithm of fibrosis as independent variables. All statistical calculations were performed with $\mathrm{R}$ software (http://www.r-project.org).

\section{RESULTS}

\section{Patient Characteristics}

Table 1 shows patient characteristics, type of surgery, and medication use for the lone $\mathrm{AF}$ and $\mathrm{AF}+\mathrm{MVD}$ groups. The echocardiographic and hemodynamic data are presented in Table 2, showing as expected, that the AF + MVD group had generally larger atrial and ventricular dimensions and higher pressures than the lone $\mathrm{AF}$ group.

\section{Atrial Interstitial Fibrosis}

Figure 2 depicts the amount of fibrous tissue in the LAA and RAA for the different groups. The mean amount of fibrous tissue in the atria (LAA and RAA combined) differs significantly among the AF + MVD, lone AF, and control groups $(13.6 \% \pm 5.8 \%, 9.7 \% \pm 3.2 \%$, and $8.8 \% \pm$ $2.4 \%$, respectively, $P<.01$ ). By using a generalized linear mixed-effects model, the following pattern emerges: The right atrium contains 1.5 times more fibrosis $(P<.001)$ than the left atrium. The atria of the AF + MVD group have 1.4 times more fibrosis than the control group $(P=.01)$ and 1.3 times more fibrosis than the lone AF group $(P=.01)$. No significant difference exists between the amount of atrial fibrosis in the lone AF and control groups. The amount of fibrous tissue in the appendages of the control group did not significantly differ from that in the free wall of the atria $(\mathrm{RAA}=10.2 \% \pm 4.0 \%$, right atrial free wall $=12.6 \% \pm 5.4 \%, P=.3 ; \mathrm{LAA}=7.5 \% \pm 2.2 \%$, left atrial free wall $=7.3 \% \pm 1.9 \%, P=.8$ ).

The amount of fibrous tissue in the RAA and LAA correlated significantly to each other $(r=0.49, P<.0001)$.
TABLE 1. Patient characteristics

\begin{tabular}{|c|c|c|c|c|}
\hline & $\begin{array}{l}\text { Lone AF } \\
(\mathbf{n}=\mathbf{8 5})\end{array}$ & $\begin{array}{c}\text { AF }+ \text { MVD } \\
(\mathbf{n}=\mathbf{2 6})\end{array}$ & $\begin{array}{l}\text { Controls } \\
(\mathbf{n}=\mathbf{1 0})\end{array}$ & $\begin{array}{c}P \\
\text { value }\end{array}$ \\
\hline Age (y) & $50.7 \pm 8.7$ & $59.0 \pm 7.6$ & $62.6 \pm 15.7$ & $\begin{array}{r}<.001 * \\
<.001 \dagger \\
\quad .470 \dagger\end{array}$ \\
\hline Male gender & $88 \%(75 / 85)$ & $65 \%(17 / 26)$ & $50 \%(5 / 10)$ & $\begin{array}{l}.016 * \\
.007 \dagger \\
.641 \ddagger\end{array}$ \\
\hline $\operatorname{BSA}\left(\mathrm{m}^{2}\right)$ & $2.11 \pm 0.20$ & $1.96 \pm 0.23$ & & .003 \\
\hline BMI $\left(\mathrm{kg} / \mathrm{m}^{2}\right)$ & $27.5 \pm 4.28$ & $24.8 \pm 3.93$ & & .005 \\
\hline Diabetes mellitus & $2 \%(2 / 85)$ & $0 \%(0 / 0)$ & & .958 \\
\hline $\begin{array}{l}\text { GFR } \\
\qquad\left(\mathrm{mL} / \mathrm{min} / 1.72 \mathrm{~m}^{2}\right) \S\end{array}$ & $81.4 \pm 14.6$ & $72.1 \pm 15.6$ & - & .011 \\
\hline AF duration (mo) & $91.3 \pm 61.3$ & $47.6 \pm 47.1$ & - & $<.001$ \\
\hline \multicolumn{5}{|l|}{ Type of AF } \\
\hline Paroxysmal & $72 \%(61 / 85)$ & $31 \%(8 / 26)$ & - & $<.001$ \\
\hline Persistent & $20 \%(17 / 85)$ & $23 \%(6 / 26)$ & & \\
\hline Permanent & $8 \%(7 / 85)$ & $46 \%(12 / 26)$ & & \\
\hline $\begin{array}{l}\text { Previous catheter } \\
\text { ablation }\end{array}$ & $15 \%(13 / 85)$ & $0 \%(0 / 26)$ & - & .076 \\
\hline \multicolumn{5}{|l|}{$\begin{array}{c}\text { Type of concomitant } \\
\text { cardiac surgery }\end{array}$} \\
\hline Mitral valve & $0 \%(0 / 85)$ & $100 \%(26 / 26)$ & - & N/A \\
\hline Tricuspid valve & $0 \%(0 / 85)$ & $15 \%(4 / 26)$ & & .002 \\
\hline CABG & $0 \%(0 / 85)$ & $4 \%(1 / 26)$ & & .529 \\
\hline ASD (all type II) & $7 \%(6 / 85)$ & $4 \%(1 / 26)$ & & .898 \\
\hline \multicolumn{5}{|l|}{ Medication use } \\
\hline Amiodarone & $62 \%(53 / 85)$ & $12 \%(3 / 26)$ & - & $<.001$ \\
\hline $\begin{array}{l}\text { Antihypertensive } \\
\text { drugs }\end{array}$ & $22 \%(19 / 85)$ & $54 \%(14 / 26)$ & & .013 \\
\hline ACEI & $20 \%(17 / 85)$ & $54 \%(14 / 26)$ & & .002 \\
\hline $\begin{array}{l}\text { Aldosterone } \\
\text { antagonist }\end{array}$ & $0 \%(0 / 0)$ & $8 \%(2 / 26)$ & & .082 \\
\hline Statin & $12 \%(10 / 85)$ & $0 \%(0 / 0)$ & & .149 \\
\hline
\end{tabular}

$B S A$, Body surface area; $B M I$, body mass index; $G F R$, glomerular filtration rate; $C A B G$, coronary artery bypass grafting; $A C E I$, angiotensin-converting enzyme inhibitor. *Lone $\mathrm{AF}$ vs $\mathrm{AF}+\mathrm{MVD}$. †Lone $\mathrm{AF}$ vs controls. $\ddagger \mathrm{AF}+\mathrm{MVD}$ vs controls. $\S$ Calculated GFR. ${ }^{13}$

\section{Predictors for Atrial Interstitial Fibrosis}

Table 3 shows the univariate analysis of different variables for the amount of fibrous tissue in the LAA and RAA. The amount of fibrous tissue correlates positively with left and right atrial diameter, left ventricular enddiastolic diameter, right ventricular systolic pressure, pulmonary artery pressures, surgery for MVD, and surgery for tricuspid valve disease, but negatively with statin use.

Figure 3 depicts scatter plots of continuous variables that significantly correlated to the amount of fibrous tissue in the LAA or RAA. Subsequent multivariate analysis showed that the following factors were independently associated with an increased amount of fibrous tissue in the LAA or RAA: surgery for tricuspid valve disease (factor 1.8 , $P=.04$ ), right atrial diameter (factor $1.02 / \mathrm{mm}, P<.01$ ), and surgery for MVD (factor $1.3, P<.01$ ). A protective 
TABLE 2. Echocardiographic data, blood pressure, and right-sided catheterization pressures

\begin{tabular}{|c|c|c|c|c|}
\hline & $\begin{array}{r}\text { Lone AF } \\
(\mathbf{n}=\mathbf{8 5})\end{array}$ & $\begin{array}{c}\mathbf{A F}+\text { MVD } \\
(\mathbf{n}=\mathbf{2 6})\end{array}$ & $\begin{array}{l}\text { Controls } \\
(\mathbf{n}=\mathbf{1 0})\end{array}$ & $P$ value \\
\hline Left atrial $\varnothing(\mathrm{mm})$ & $42.3 \pm 7.1$ & $53.7 \pm 9.0$ & - & $<.001$ \\
\hline Right atrial $\varnothing(\mathrm{mm})$ & $53.5 \pm 5.6$ & $59.9 \pm 11.5$ & - & .021 \\
\hline LVEDD (mm) & $50.2 \pm 5.6$ & $58.8 \pm 9.8$ & - & $<.001$ \\
\hline LVESD (mm) & $35.4 \pm 5.2$ & $43.0 \pm 8.4$ & - & $<.001$ \\
\hline \multicolumn{5}{|l|}{ LVEF } \\
\hline$>50 \%$ & $94 \%(80 / 85)$ & $81 \%(21 / 26)$ & - & .097 \\
\hline $40 \%-50 \%$ & $4 \%(3 / 85)$ & $15 \%(4 / 26)$ & & \\
\hline $30-40 \%$ & $2 \%(2 / 85)$ & $4 \%(1 / 26)$ & & \\
\hline $\begin{array}{c}\text { Blood pressure } \\
\text { (mm Hg) }\end{array}$ & & & - & \\
\hline Systolic & $135 \pm 17$ & $133 \pm 19$ & & .695 \\
\hline Diastolic & $83 \pm 9$ & $79 \pm 8$ & & .028 \\
\hline Mean & $100 \pm 11$ & $97 \pm 11$ & & .182 \\
\hline $\begin{array}{l}\text { Catheterization } \\
\text { pressures }(\mathrm{mm} \mathrm{Hg})\end{array}$ & & & - & \\
\hline Right atrium mean & $4.6 \pm 2.9$ & $5.3 \pm 4.0$ & & 454 \\
\hline Wedge & $9.4 \pm 3.9$ & $19.9 \pm 8.0$ & & $<.001$ \\
\hline RV systolic & $25.7 \pm 6.2$ & $48.7 \pm 25.6$ & & .001 \\
\hline LV end systolic & $130 \pm 22$ & $131 \pm 29$ & & .940 \\
\hline LV end diastolic & $10.4 \pm 4.9$ & $13.3 \pm 6.4$ & & .063 \\
\hline Systolic PAP & $25.1 \pm 6.6$ & $45.0 \pm 15.8$ & & $<.001$ \\
\hline Diastolic PAP & $9.3 \pm 4.1$ & $19.0 \pm 9.0$ & & $<.001$ \\
\hline Mean PAP & $15.6 \pm 4.9$ & $27.3 \pm 10.7$ & & $<.001$ \\
\hline
\end{tabular}

$\phi$, Diameter; $L V E D D$, left ventricular end-diastolic diameter; $L V E S D$, left ventricular end-systolic diameter; $L V E F$, left ventricular ejection fraction; $R V$, right ventricle; $L V$, left ventricle; $P A P$, pulmonary artery pressure.

trend was found for the use of statins with an estimated increase of fibrous tissue of $0.76(P=.06)$.

For the average amount of fibrosis (RAA and LAA combined), surgery for MVD was the only remaining significant predictor. Patients with surgery for MVD had a 1.7 estimated increase of fibrous tissue $(P<.01)$.

\section{DISCUSSION}

It is well recognized that fibrous tissue can play an important role in the pathogenesis of $\mathrm{AF}^{2-5}$ On the other hand, $\mathrm{AF}$ itself may result in fibrosis. ${ }^{2}$ The main finding of this study is that patients with AF and MVD have more atrial fibrosis than patients with lone AF. Furthermore, no difference in atrial fibrosis was found between patients with lone AF and controls. This suggests that AF itself does not result in fibrosis in patients with lone $\mathrm{AF}$ and that the mechanism of the arrhythmia in these patients is more likely to be related to electrical or autonomic remodeling. This is further endorsed by the multivariate analysis, which found no relation between fibrosis and duration of AF; however, we cannot exclude that structural changes different from fibrosis play a role in lone AF.

In our study, the amount of fibrous tissue in the LAA and RAA did not significantly differ from that of the corresponding left and right atrial free wall. Our findings in the

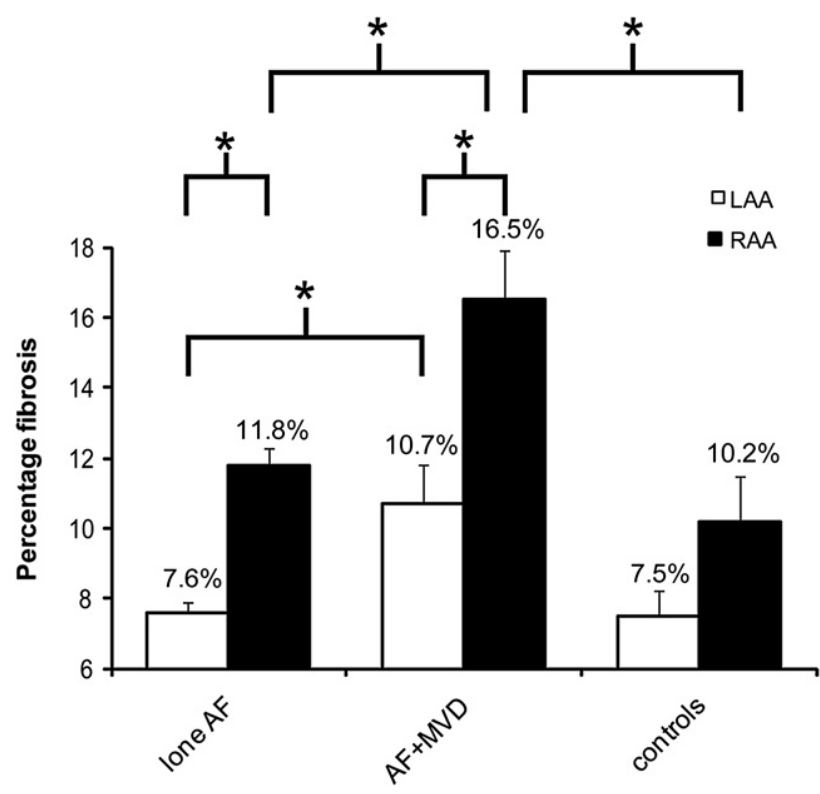

FIGURE 2. Amount of fibrous tissue in LAA and RAA per group. Perivascular, endocardial fibrosis, and epicardial fibrosis were excluded. Values are given as percentage with the standard error of the mean (error bars). ${ }^{*} P<.05$. LAA, Left atrial appendage; $R A A$, right atrial appendage; $A F$, atrial fibrillation; $M V D$, mitral valve disease.

atrial appendages may therefore be extrapolated to the atrial free wall.

This study also showed that the right atrium contains more fibrous tissue than the left atrium. This finding is concordant with the results of Oken and Boucek, ${ }^{14}$ who showed that both the right ventricle and the atrium contain more fibrous tissue than the left ventricle and atrium. We speculate that the difference in the amount of fibrous tissue between the right and the left atrium has a developmental origin. First, the right atrium has a different embryonic identity than the left atrium. ${ }^{15}$ Second, the pressures of the right side of the heart are higher than the left side during fetal circulation. ${ }^{16}$

This study showed a trend toward a negative correlation between statins and atrial fibrosis. The protective role of statins in the prevention of AF has been recognized, but the exact pathophysiology of its protective role is unknown. ${ }^{17,18}$ Fibrosis has been suggested to play a role in this matter. ${ }^{19}$ To our knowledge, this is the first study to describe a negative relation between statin use and amount of atrial interstitial fibrosis.

\section{Substrate and Trigger}

This study showed that patients with AF and MVD have more interstitial fibrosis than patients with lone AF. This is probably the explanation for the relatively low success rate of antiarrhythmic surgery in patients with AF and MVD, especially when only a pulmonary vein isolation is performed. ${ }^{7}$ The greater amount of fibrosis in patients with 
TABLE 3. Univariate analysis for the fibrous content in both atria (pooled)

\begin{tabular}{|c|c|c|c|c|c|}
\hline Predictors of fibrosis & $\begin{array}{c}\text { Estimate } \\
(\log )\end{array}$ & $\begin{array}{c}\text { CI } \\
\text { lower }\end{array}$ & $\begin{array}{c}\text { CI } \\
\text { upper }\end{array}$ & Missing & $\begin{array}{c}P \\
\text { values }\end{array}$ \\
\hline Age & 0.002 & -0.006 & 0.010 & 0 & 6798 \\
\hline Male gender & -0.174 & -0.368 & 0.020 & $\mathbf{0}$ & .0779 \\
\hline BSA & -0.175 & -0.520 & 0.170 & 1 & .3165 \\
\hline BMI & -0.010 & -0.027 & 0.007 & 1 & .2435 \\
\hline Diabetes mellitus & 0.077 & -0.480 & 0.633 & 0 & .7855 \\
\hline GFR & 0.003 & -0.002 & 0.007 & 0 & .3084 \\
\hline AF duration* & 0.039 & -0.112 & 0.189 & 2 & .6107 \\
\hline Type $\mathbf{A F} \dagger$ & 0.130 & -0.020 & 0.281 & $\mathbf{0}$ & .0896 \\
\hline $\begin{array}{l}\text { Previous catheter } \\
\text { ablation } \ddagger\end{array}$ & 0.044 & -0.186 & 0.274 & 0 & .7053 \\
\hline Left atrial $\varnothing$ & 0.009 & 0.001 & 0.017 & 1 & .0338 \\
\hline Right atrial $\varnothing$ & 0.016 & 0.006 & 0.026 & 12 & 0014 \\
\hline LVEDD & 0.012 & 0.002 & 0.022 & 9 & 0224 \\
\hline LVF§ & 0.046 & -0.141 & 0.232 & 0 & .6280 \\
\hline Blood pressure, systolic & -0.001 & -0.005 & 0.003 & 0 & .6723 \\
\hline Blood pressure, diastolic & -0.007 & -0.016 & 0.001 & 0 & .1032 \\
\hline Blood pressure, mean & -0.004 & -0.011 & 0.003 & 0 & .2746 \\
\hline Right atrium pressure & 0.004 & -0.025 & 0.033 & 26 & .7734 \\
\hline Wedge pressure & 0.008 & -0.004 & 0.021 & 22 & .1960 \\
\hline RV systolic pressure & 0.005 & 0.000 & 0.010 & 31 & .0427 \\
\hline LV end-systolic pressure & 0.001 & -0.002 & 0.005 & 11 & .5202 \\
\hline LV end-diastolic pressure & 0.007 & -0.009 & 0.023 & 19 & .3862 \\
\hline PAP systolic & 0.008 & 0.002 & 0.015 & 20 & .0127 \\
\hline PAP diastolic & 0.007 & -0.005 & 0.020 & 20 & .2285 \\
\hline PAP mean & 0.013 & 0.002 & 0.024 & 28 & .0184 \\
\hline Amiodarone & -0.118 & -0.265 & 0.028 & 0 & .1116 \\
\hline Antihypertensive drugs & 0.129 & -0.033 & 0.290 & 0 & .1170 \\
\hline ACEI & 0.087 & -0.077 & 0.251 & 0 & 0.2949 \\
\hline Aldosterone antagonist & -0.136 & -0.692 & 0.420 & 0 & .6298 \\
\hline Statin & -0.264 & -0.517 & -0.010 & $\mathbf{0}$ & .0419 \\
\hline Mitral valve surgery & 0.299 & 0.134 & 0.464 & $\mathbf{0}$ & .0005 \\
\hline Tricuspid valve surgery & 0.419 & $\mathbf{0 . 0 3 0}$ & 0.808 & $\mathbf{0}$ & .0351 \\
\hline ASD type II closure & -0.044 & -0.349 & 0.260 & 0 & .7727 \\
\hline
\end{tabular}

Estimate denotes beta regression parameter as a measure of association. Values in bold text were applicable for multivariate analysis $(P<.1)$. $\phi$, Diameter; $L V E D D$, left ventricular end-diastolic diameter; $L V E S D$, left ventricular end-systolic diameter; $L V E F$, left ventricular ejection fraction; $R V$, right ventricle; $L V$, left ventricle; $C I$, confidence interval; $P A P$, pulmonary artery pressure. *History of $\mathrm{AF}<5 \mathrm{vs}>5$ years. $\dagger$ Paroxysmal versus continuous (persistent and permanent) AF. $\ddagger$ Either pulmonary vein isolation or right-sided isthmus ablation in history. §Divided into groups of an ejection fraction of $>50 \%, 40 \%-50 \%$, or $30 \%-40 \%$.

$\mathrm{AF}$ and MVD also potentially explains why those patients have relatively more persistent and permanent AF than patients with lone AF, despite their shorter history of AF (Table 1).

The increased amount of fibrous tissue in the atria of patients with AF secondary to MVD might be due to increased wall stress. ${ }^{6,20}$ The wall stress is dependent on both the pressure and diameter of the atrium (Laplace's law), and these were both significantly larger in the AF + MVD group compared with the lone AF group. However, increased fibrosis in patients with AF secondary to MVD also may be due to heart failure. ${ }^{21}$ The AF + MVD group had larger left ventricular dimensions and an impaired glomerular filtration rate, which suggests at least some systolic heart failure.

\section{Age and Fibrosis}

Because the mean age of patients with AF + MVD exceeded that of patients with lone AF, one could argue that differences in atrial fibrosis between the groups rely on age differences. However, the multivariate analysis showed that MVD is associated with a $72 \%$ increase in atrial fibrosis $(P<.01)$ and that age was not related to the amount of fibrosis $(P=.7)$. Even when we limit the analysis to the 5 youngest patients of the control group (aged $50.4 \pm 11.2$ years), there is no significant difference in the amount of fibrous tissue between the control and lone AF groups (aged $50.7 \pm 8.7$ years).

Evidence for age-related human atrial fibrosis is scarce and conflicting. Although 2 studies have found a relation between age and atrial fibrosis, ${ }^{22,23}$ others have not. ${ }^{15,21}$ The relation between age and fibrosis in these studies could be attributed to the increased prevalence of other cardiovascular diseases in elderly people, such as hypertension, coronary artery disease, heart failure, and cardiac valve pathology. Furthermore, it could be that the distribution of age (52 \pm 9 years) in this study was too small to find an increase of fibrosis with age, which is often the case in animal studies.

\section{Fibrosis and Atrial Fibrillation}

Recent magnetic resonance imaging studies showed that the success after a percutaneous vascular intervention depends on the late enhancement of the left atrial wall, which correlates to the amount of fibrous tissue. ${ }^{24}$ Our study showed that the right atrium contains more fibrous tissue than the left atrium. This underscores the importance of inclusion of the right atrium in the surgical treatment of AF, especially in patients with MVD. The Maze III operation modifies the substrate in both atria and is still considered as the golden standard for nonpharmacologic treatment of $\mathrm{AF}$ with a reported long-term success of more than $90 \%{ }^{7,11}$

\section{Limitations}

Because of the small wall thickness of the atria, we were unable to make parallel sections and could not discriminate among patchy, diffuse, and compact fibrosis. These different types of fibrosis have different electrophysiologic effects. ${ }^{10}$ However, no compact fibrosis was encountered in the transverse sections.

This study shows no increase in fibrous tissue for patients with lone AF compared with controls. We cannot exclude that a different geometry of the fibrous tissue or other types of structural remodeling (eg, $\mathrm{Cx} 43$ expression) play a role in these patients. 

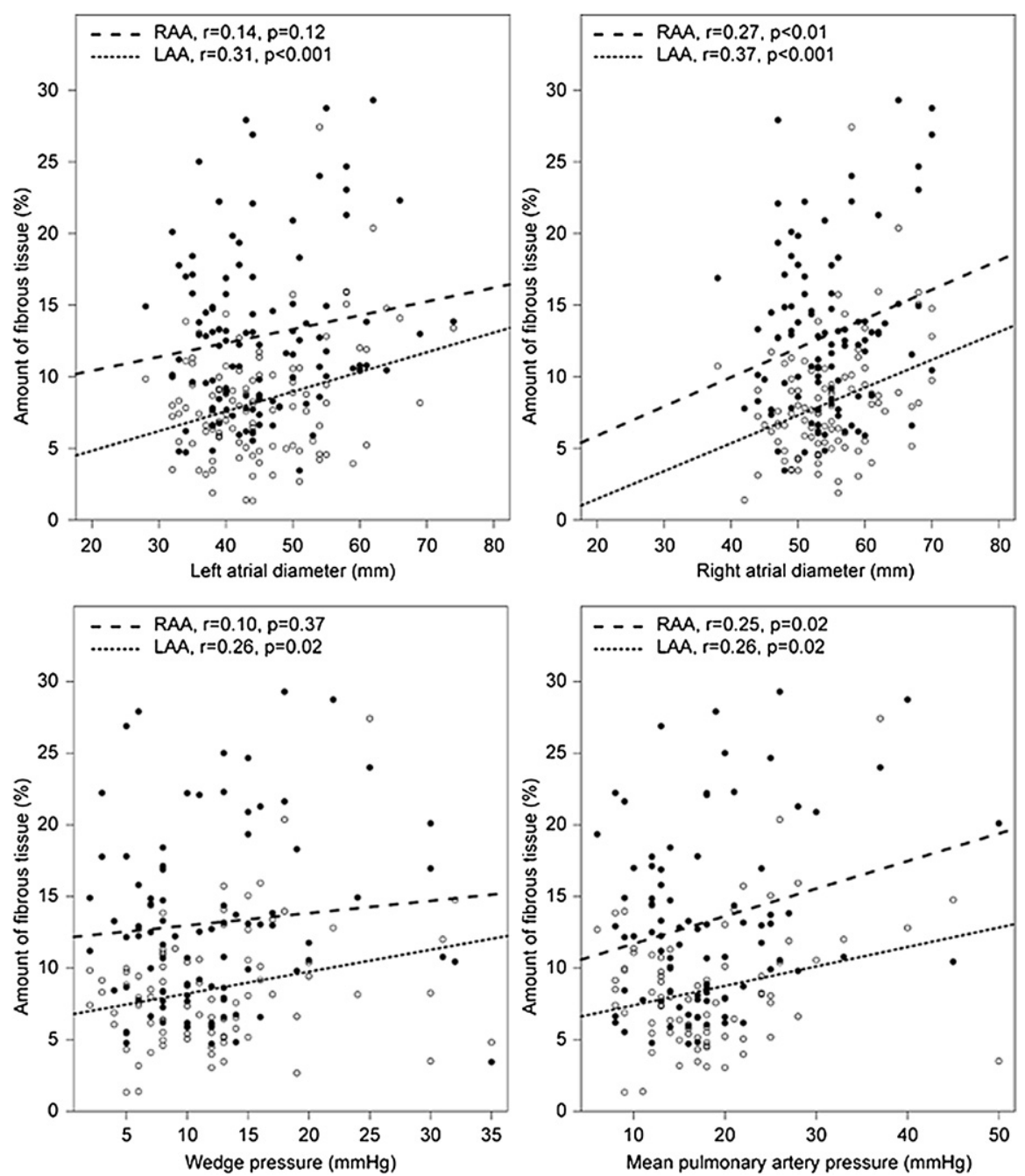

FIGURE 3. Scatter plots of different continuous variables in relation with the amount of interstitial fibrosis in the LAA or RAA. Other continuous variables that correlated significantly with the amount of fibrosis, but not displayed, are as follows: LVEDD: RAA; $r=0.21, P=.03$, LAA; $r=0.28, P<.01$. Right ventricular systolic pressure: RAA; $r=0.27, P=.02$, LAA; $r=0.34, P<.01$. Systolic pulmonary artery pressure: RAA; $r=0.25, P=.02$, LAA; $r=0.30$, $P<.01$. $L A A$, Left atrial appendage; $R A A$, right atrial appendage.

Differences in age and other baseline characteristics existed between the groups because of selection of the patient population. Meticulous analysis showed no relation between age and fibrosis, but we cannot exclude that unrecorded differences in baseline characteristics interfered with our results.

The amount of fibrous tissue in the lone $\mathrm{AF}$ and $\mathrm{AF}+$ MVD groups was determined at the base of the atrial appendages and not in the atria itself. Although no difference existed in the control group, a discrepancy in the amount of fibrous tissue between the appendages and atria could exist in these 2 groups.

\section{CONCLUSIONS}

The atria of patients with AF secondary to or in combination with MVD contain more fibrous tissue than atria of patients with lone AF, whereas atria of patients with lone $\mathrm{AF}$ have an equal amount of fibrous tissue as controls. In general, the right atrium contains more fibrous tissue than the left atrium. These findings suggest that AF secondary to or in combination with MVD is dependent on atrial interstitial fibrosis, whereas lone AF is more dependent on electrical or autonomic remodeling. This suggests that for treatment of AF secondary to MVD, a different percutaneous or surgical approach should be applied than in lone AF. Furthermore, statins may reduce the amount of fibrous tissue in the atria and are therefore of interest in pharmacologic therapy for the prevention of AF.

The authors thank P.C. de Bruin of the Pathology Department for work that made this article possible. 


\section{References}

1. Lloyd-Jones DM, Wang TJ, Leip EP, Larson MG, Levy D, Vasan RS, et al. Lifetime risk for development of atrial fibrillation: the Framingham Heart Study. Circulation. 2004;110:1042-6.

2. Allessie M, Ausma J, Schotten U. Electrical, contractile and structural remodeling during atrial fibrillation. Cardiovasc Res. 2002;54:230-46.

3. Frustaci A, Chimenti C, Bellocci F, Morgante E, Russo MA, Maseri A. Histological substrate of atrial biopsies in patients with lone atrial fibrillation. Circulation. 1997;96:1180-4

4. Boldt A, Wetzel U, Lauschke J, Weigl J, Gummert J, Hindricks G, et al. Fibrosis in left atrial tissue of patients with atrial fibrillation with and without underlying mitral valve disease. Heart. 2004;90:400-5.

5. Verheule S, Sato T, Everett T 4th, Engle SK, Otten D, Rubart-von der Lohe M, et al. Increased vulnerability to atrial fibrillation in transgenic mice with selective atrial fibrosis caused by overexpression of TGF-beta1. Circ Res. 2004;94: 1458-65.

6. Verheule S, Wilson E, Everett T 4th, Shanbhag S, Golden C, Olgin J. Alterations in atrial electrophysiology and tissue structure in a canine model of chronic atrial dilatation due to mitral regurgitation. Circulation. 2003;107:2615-22.

7. Geuzebroek GS, Ballaux PK, van Hemel NM, Kelder JC, Defauw JJ. Mediumterm outcome of different surgical methods to cure atrial fibrillation: is less worse? Interact Cardiovasc Thorac Surg. 2008;7:201-6.

8. de Bakker JM, van Capelle FJ, Janse MJ, Tasseron S, Vermeulen JT, de Jonge N, et al. Slow conduction in the infarcted human heart. 'Zigzag' course of activation. Circulation. 1993;88:915-26.

9. Spach MS, Josephson ME. Initiating reentry: the role on nonuniform anisotropy in small circuits. J Cardiovasc Electrophysiol. 1994;5:182-209.

10. Kawara T, Derksen R, de Groot JR, Coronel R, Tasseron S, Linnenbank AC, et al. Activation delay after premature stimulation in chronically diseased human myocardium relates to the architecture of interstitial fibrosis. Circulation. 2001;104: 3069-75.

11. Ballaux PK, Geuzebroek GS, van Hemel NM, Kelder JC, Dossche KM, Ernst JM, et al. Freedom from atrial arrhythmias after classic maze III surgery: a 10-year experience. J Thorac Cardiovasc Surg. 2006;132:1433-40.

12. Calkins H, Brugada J, Packer DL, Cappato R, Chen SA, Crijns HJ, et al., European Heart Rhythm Association (EHRA); European Cardiac Arrhythmia Scoiety (ECAS); American College of Cardiology (ACC); American Heart Association (AHA); Society of Thoracic Surgeons (STS). HRS/EHRA/ECAS expert Consen- sus Statement on catheter and surgical ablation of atrial fibrillation: recommendations for personnel, policy, procedures and follow-up. A report of the Heart Rhythm Society (HRS) Task Force on catheter and surgical ablation of atrial fibrillation. Heart Rhythm. 2007;4:816-61.

13. Levey AS, Bosch JP, Lewis JB, Greene T, Rogers N, Roth D. A more accurate method to estimate glomerular filtration rate from serum creatinine: a new prediction equation. Modification of Diet in Renal Disease Study Group. Ann Intern Med. 1999;130:461-70.

14. Oken DE, Boucek RJ. Quantitation of collagen in human myocardium. Circ Res. 1957:5:357-61.

15. Franco D, Campione M. The role of Pitx2 during cardiac development. Linking left-right signaling and congenital heart diseases. Trends Cardiovasc Med. 2003; 13:157-63.

16. Abdul-Karim R. Fetal physiology—a review. Obstet Gynecol Surv. 1968;23: 713-45.

17. Fauchier L, Pierre B, de Labriolle A, Grimard C, Zannad N, Babuty D. Antiarrhythmic effect of statin therapy and atrial fibrillation a meta-analysis of randomized controlled trials. J Am Coll Cardiol. 2008;51:828-35.

18. Winchester DE, Wen X, Xie L, Bavry AA. Evidence of pre-procedural statin therapy a meta-analysis of randomized trials. J Am Coll Cardiol. 2010;56 1099-109.

19. Kostapanos MS, Liberopoulos EN, Goudevenos JA, Mikhailidis DP, Elisaf MS. Do statins have an antiarrhythmic activity? Cardiovasc Res. 2007;75:10-20.

20. Schotten U, Neuberger HR, Allessie MA. The role of atrial dilatation in the domestication of atrial fibrillation. Prog Biophys Mol Biol. 2003;82:151-62.

21. Barasch E, Gottdiener JS, Aurigemma G, Kitzman DW, Han J, Kop WJ, et al. Association between elevated fibrosis markers and heart failure in the elderly: the cardiovascular health study. Circ Heart Fail. 2009;2:303-10.

22. Nakai T, Chandy J, Nakai K, Bellows WH, Flachsbart K, Lee RJ, et al. Histologic assessment of right atrial appendage myocardium in patients with atrial fibrillation after coronary artery bypass graft surgery. Cardiology. 2007;108:90-6.

23. Gramley F, Lorenzen J, Knackstedt C, Rana OR, Saygili E, Frechen D, et al. Agerelated atrial fibrosis. Age (Dordr). 2009;31:27-38.

24. Mahnkopf C, Badger TJ, Burgon NS, Daccarett M, Haslam TS, Badger CT, et al. Evaluation of the left atrial substrate in patients with lone atrial fibrillation using delayed-enhanced MRI: implications for disease progression and response to catheter ablation. Heart Rhythm. 2010;7:1475-81. 